\title{
Waste Management on Board Disney Cruise Line Company Ships
}

\author{
Valentina-Mariana Mănoiu ${ }^{1}$, Alexandru-Ioan Crăciun ${ }^{2, \bigotimes}$ \\ ${ }^{1}$ University of Bucharest, Faculty of Geography, Bucharest, Romania \\ ${ }^{1}$ Pro Biodiversitas, Bucharest, Romania
}

\begin{abstract}
This article presents the waste management on board Disney Cruise Line (DCL) company ships. In previous papers, we focused on the environmental policies of the DCL company, on the cruise itinerary waste management plans for the enterprise's ships, waste collection, sorting and storage and food waste management on DCL ships, as well as on dangerous and medical waste management on board DCL company ships. The paper consists of an analytical view of the environmental personnel's activities, in-house regulations and of various recordings and field observations. It presents detailed information on waste collection, sorting and transportation on board company ships, as well as on waste processing, storage and disposal procedures, waste registers and reports filed by employees, White Data Box and the equipment used for waste processing and recycling. The study concludes that the DCL company is committed to minimizing its fleet's environmental impact by means of adopting new technologies, generating less waste, training its staff and instructing its guests, and raising awareness on environmental issues. In 2013, the company was declared the most environmentally-responsible cruise line. All crew members must fully comply with the DCL company's environmental requirements and policy. Both employees and customers must pay attention to the practices that can result in accidental pollution. Waste collection procedures and the prevention of improper waste disposal are carefully monitored at all times. DCL makes continuous efforts to minimize waste amounts and associated risks on its ships. This entails using the appropriate storage, use and disposal procedures, and extends all the way to operation and event planning and supply and consumable purchases. DCL's environmentally friendly vision is best described by these values and actions: thorough bookkeeping, monitoring, double-checking, awareness, continuous communication.
\end{abstract}

Keywords: Disney Cruise Line, environmental policy, waste management.

CORRESPONDENCE:

valentina.mariana.manoiu@gmail.com (V.-M. M.), alexandru.ioan.craciun@gmail.com (A.-I. C.) 


\section{Introduction}

Over time, environmental challenges have become increasingly apparent and more and more people and companies worldwide are actively trying to make a difference. Preventing ecological degradation entails, among others, defining and implementing policies and plans that ensure both environmental protection and economic growth. Sustainable development is one of the main environmental concepts today, aimed at integrating environment-related conditions and standards into all global policies. Companies that adhere to this principle have a good chance of building sound reputations and high trading value.

The present paper presents the waste management on the Disney Cruise Line (DCL) company ships. In the previous papers, we focused on the environmental policies of the DCL company (Manoiu, Antonescu, 2017), on the cruise itinerary waste management plans for the enterprise's ships (Manoiu, Antonescu, 2017), waste collection, sorting and storage and food waste management on DCL ships (Manoiu, 2018), as well as on dangerous and medical waste management on board DCL company ships (Manoiu, 2018, accepted article ADVED 2018).

The purpose of this paper is to describe the active environmental impact prevention measures DCL uses and to analyze the collection, sorting, transportation, processing, storage and discharge procedures used for waste generated on board, as well as waste registers and reports, White Data Box and the equipment employed for waste processing and recycling. Disney Cruise Line is an enterprise affiliated with the Walt Disney Company (Manoiu, Antonescu, 2017). It was founded in 1996, initially under the name Magical Cruise Company Limited, based in London, UK, with its operational headquarters in Celebration, Florida (Manoiu, Antonescu, 2017). At present, the DCL holds four cruise ships (Manoiu, Antonescu, 2017): Disney Magic, Disney Wonder, Disney Dream, and Disney Fantasy.

The environmental responsibilities on board DCL ships are attributed to the captain, the environmental officer, the chief engineer, the B mechanic, and finally to all crew members (Manoiu, Antonescu, 2017).

The article, through its originality, is meant to add to the understudied topic of cruise ship waste management systems (Letson, Suman, Shivlani, 1998; Johnson, 2002; Morehouse, Koch, 2003; Polglaze, 2003; Butt, 2007; Srinivasan, Swain, 2007; Brida, Zapata, 2010; Burgin, Hardiman, 2011; Ulnikovic et al., 2012; Kizielewicz, Lukovic, 2015; Lasserre, Tetu, 2015; Strazza, Del Borghi, Gallo, Manariti, Missanelli, 2015; Wilewska-Bien, Granhag, Andersson, 2016; Svaetichin, Inkinen, 2017). The present and previous papers contain relevant data sourced from official documents and records, coupled with the contribution of in-house environmental staff, corporate guidelines and field observations that focus on the waste management system put in place on cruise routes and on board the ships. 


\section{Collection, sorting and transportation of waste to the treatment area on board DCL cruise ships}

This chapter presents and analyses waste collection, sorting and transportation procedures used in several ship units.

\subsection{Waste collection and sorting}

All units have designated areas for waste collection, from which the waste is then transferred to the treatment area (Disney Cruise Line, 2016). Metal containers are provided for each type of waste (Table 1):

Table 1: Types of waste

\begin{tabular}{lll}
\hline Category & Examples & Color of container \\
\hline Burnable materials & Paper, plastic, rags & Blue/Aluminum \\
Glass & Bottles, glasses, mugs, plates & Gray \\
Cans and metal & Aluminum and metal cans & Green \\
Food & Cooked or raw food & Yellow \\
Medical & Blood-contaminated bandages & Red \\
Cooking oils & Used cooking oil & Black \\
\hline
\end{tabular}

Source: Disney Cruise Line, 2016.

If a given item does not fit any of the signaled waste categories, it must be taken directly to the waste processing area. All crew members must sort waste in the unit where it is generated (Disney Cruise Line, 2016), i.e. work areas, cabins, restaurants/pubs, and recreational facilities. Crew members must transfer the waste they generate to the designated collection point or directly to the waste processing area.

\subsection{Transportation to the waste treatment area}

For sanitary and safety reasons, collected waste must reach the waste processing area as directly as possible. Heads of unit must train their personnel on waste transportation methods and routes (Disney Cruise Line, 2016). When crew members reach the processing area, they are given instructions based on the type of waste they are transferring. Afterwards, they must wash the containers and take them back to their designated locations. This procedure for waste container use must be followed by each unit.

\subsection{Departmental responsibilities}

Waste management is an unequivocal responsibility of all employees and units. Failure to comply can lead to disciplinary actions or even termination (Disney Cruise Line, 2016). 
All heads of unit must check: that waste collection points are set up with appropriate containers for each operation, that efficient procedures for sorting and transporting waste to the waste treatment area are put in place, and that all crew members are trained on the correct waste management methods.

\section{On board waste storage}

\subsection{Waste processing area}

The waste processing area is fitted with a) an incinerator sector; b) a waste sorting and storage area, and c) a waste cold storage room.

The waste processing area must be kept clean and closely monitored at all times.

\subsection{Types of processed waste}

\section{Burnable waste}

When a waste load is transferred to the processing area, the types of materials must be identified in order to choose the right processing method. All burnable waste must be shredded before being incinerated. According to United Nations International Maritime Organization specifications (2011), on board incineration is not fit for the following: polychlorinated biphenyls (PCBs); waste containing traces of heavy metals; refined petroleum-based products containing halogen compounds.

Non-burnable waste

Non-dangerous non-burnable waste is stored temporarily until it can either be recycled or unloaded on land.

\section{Recyclable waste}

Such waste must be sorted before being transferred to the waste processing area. Recyclable materials must be kept and unloaded separately; otherwise the recycling process can be slowed down.

\section{Food waste}

Food waste is normally processed on board by means of grinders. All items not fit for grinding are transferred to the waste processing area for cold storage and unloading.

\section{Special waste}

Any material classified as special waste is not fit for on board processing. As such, it must be transferred to the waste processing area where it will be packaged and stored until unloading is possible. 


\subsection{On board waste storage}

The two main units are the cold storage room and the waste sorting and storage area (Fig. 1).

The environmental officer must oversee and coordinate all waste sorting and labeling procedures in the processing area (Disney Cruise Line, 2016). Waste processing unit employees are instructed by the environmental officer on all waste handling operations.

\section{Waste cold storage room}

While this unit is primarily used for waste that biodegrades (food waste), it can also accommodate other types of waste (e.g. dangerous non-flammable waste), assessed on a case-by-case basis. Storage for dangerous waste must not exceed 90 days. As part of the storage process, the environmental officer must verify that labels are accurate, the proper containers were used, material safety data sheets (MSDS) are duly filled out and that all incompatible materials are removed (Disney Cruise Line, 2016). Labeling must feature the dates of storage to avoid exceeding the 90-day limit.

Safety measures must be taken to cover all risks associated to the various types of waste that are stored at any given time. The legally-required equipment consists of: a fire extinguisher, personal protective equipment (PPE), and MSDS that explicitly mention any hazardous elements (Disney Cruise Line, 2016).

\section{Waste processing and discharge procedures}

\subsection{Food waste}

Food waste processing and discharge procedures were presented in a previous paper (Manoiu, 2018).

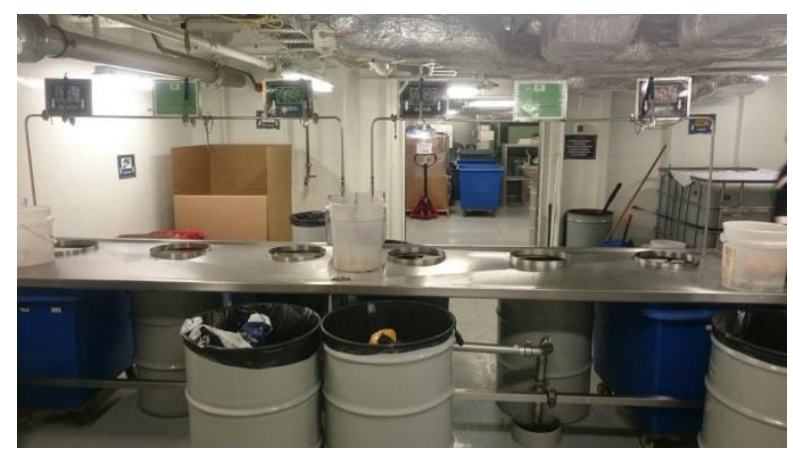

Figure 1: Waste sorting unit

\subsection{Dangerous waste}

4.2.1. Dangerous Waste Management 
According to the US Environmental Protection Agency, a part of waste that is normally generated on board is dangerous, i.e. given the nature of the waste's composition, if not processed and discharged appropriately, it has the potential of being harmful to human health and/or to the environment.

The DCL ship fleet is classified as a small generator of dangerous waste, which means the company can discharge a monthly amount of $1000 \mathrm{~kg} / \mathrm{ship}$. If this amount is exceeded, the Environmental Officer has the obligation to notify the Logistics Officer, who in turn will request instructions from the Safety, Security and Environmental Policy Department.

\subsubsection{Dangerous waste storage and packaging}

Before the final discharge, all dangerous waste, other than flammable waste, and materials that, for any reason, cannot be processed on board, must be moved to the waste processing area or to any other location the Environmental Officer deems appropriate for storage and packaging.

Non-flammable dangerous waste must be stored in the cold storage room, and the maximum storage period for dangerous waste in this unit is ninety days (Manoiu, 2018). For storing dangerous waste on board, special containers must be used.

Before being transferred to the storage area, all dangerous waste must be verified by the environmental officer whose checklist includes: confirming the labeling was done correctly, the appropriate containers for this particular type of waste were used and that they do not feature any flaws, making sure MSDS are available, and extracting incompatible materials.

In order to discharge the containers, the environmental officer contacts the logistics officer, who makes the necessary discharge and transfer arrangements.

\subsubsection{Discharge of dangerous waste on land}

The Environmental Officer must at all times keep track of the amount of dangerous waste and the on board storage duration, so as to make sure the 90-day limit is not exceeded.

For discharging dangerous waste, the environmental officer prepares the paperwork and requests the Staff Captain's approval. Then, at least 7 days before docking, the Environmental Officer submits a preliminary report to the logistics and procurement department, which must mention the date and time of discharge, number of containers, contents, and the number of required empty containers (if necessary). The logistics and procurement department then notifies the waste processing company and sets up the transfer. 
One day before the ship reaches destination, the environmental officer sends the Shipboard Pro Forma Invoice to the Hotel Stores Manager and informs local authorities about the upcoming waste discharge operation.

The logistics department must receive a copy of the transfer's customs papers.

The environmental officer must check once more that the waste was packed and labeled correctly, and that a copy of the customs papers is available. When empty containers are requested, the environmental officer oversees the on board transfer. When the company reaches the designated location, the environmental officer notifies the customs officer upon starting the discharge procedure, checks the paperwork and performs a final inspection of the containers joined by a waste processing company representative.

If both parties confirm that the specifications and documentation are in order, the waste is transferred from the ship directly to the transportation vehicle. The environmental officer must make sure that the dangerous waste is taken by contracting company (without the involvement of any other entity).

When the waste transfer to the vehicle is completed, a report is filed and annexed to the Hazardous Waste Log, which is used by the environmental officer for keeping a record of all dangerous waste discharges.

Within 30 days of the transfer, the contracting company must submit a copy of the report to the logistics and procurement department in order to certify compliance with all local regulations in force. The environmental officer must receive the original document, which will be annexed to the Hazardous Waste Log. All documentation pertaining to dangerous waste must be kept on board for at least 3 years.

\subsubsection{Procedures for waste with particular characteristics}

Some of the different types of waste that are generated on a ship require special care before they can be discharged onshore.

Dangerous waste must be transferred, stored and treated under the conditions specified in the relevant regulations on dangerous substances in force (U.S. Government Publishing Office site, 40 CFR 261.33).

Several types of special waste can undergo treatment on board and, once the dangerous substances are removed, they no longer need to be discharged as dangerous waste - e.g. photographic waste treated for removing silver and aerosol tubes/cans that have been punctured are taken out of the dangerous class. A separate procedure for potentially dangerous waste is periodically testing for dangerous elements - e.g. incinerator ash.

\subsubsection{Responsibilities}


All ship departments are accountable for the dangerous waste they generate.

A ship's environmental officer is in charge of planning and overseeing the entire series of dangerous waste management procedures (collection, labeling, transfer, storage and discharge), as well as of the preparation of the necessary papers. He or she has the obligation to make sure all types of waste are classified correctly and accompanied by the appropriate discharge instructions. Information on necessary precautions and discharge procedures can be included in the MSDS. Unknown types of waste will automatically be considered dangerous until they are identified. When dangerous waste is generated in a given unit, the head of unit must file a waste transfer form with the environmental officer in order to initiate the discharge procedure. The head of unit is in charge of checking that labeling and packaging were done properly and that the MSDS was prepared. The environmental officer can then plan the transfer.

\subsubsection{Discharge of dangerous waste as a matter of urgency}

In case a given type of dangerous waste must be discharged urgently, the environmental officer must notify the ship Captain, the logistics and procurement department, as well as the Department of Maritime and Technical Operations. A thorough description of the dangerous waste is then submitted to the waste collection company. The logistics department must set a transfer date together with the collection company, and inform the Staff Captain, Environmental Officer, Department of Maritime and Technical Operations, and the DCL incident center on the established date. These internal procedures are followed by the standard transfer operations, including reporting and logging.

\subsection{Special waste}

Any given ship features several waste streams that, if discarded inappropriately, are harmful to the marine environment. They require special attention upon disposal. Some types of waste can be processed or tested on board to check the extent to which they are dangerous or to remove any hazardous characteristics before disposal.

\subsubsection{Photocopying and print waste}

While photocopying and toner cartridge waste is not dangerous, it does require special disposal procedures. It can be recycled by the producer on land. All cartridges must be sent to the waste treatment unit as recyclable materials. They will be kept in the storage area until the minimum amount for recycling is reached. Used cartridges must not be mixed with any other type of waste. Any ink used on board the ship must be classified as hazardous waste (Fig. 2). 


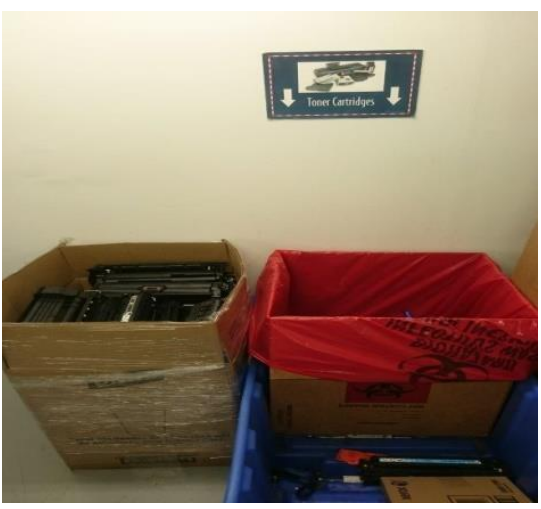

Figure 2: Separate collection of cartridges

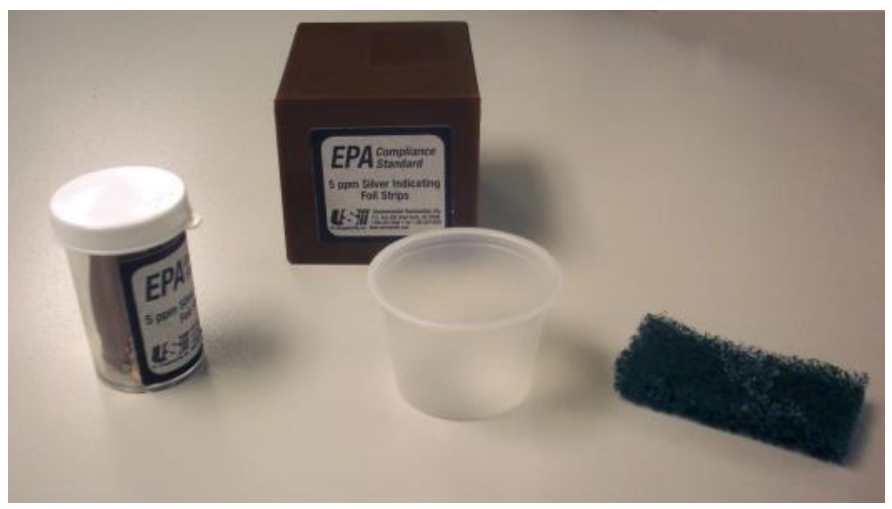

Figure 3: Silver content test equipment

\subsubsection{Photographic waste}

Photographic waste can contain silver traces that would make it dangerous. The level of this contaminant can be decreased in order to change the waste category from dangerous to industrial waste. If the photographic waste can be processed so that the silver content is lowered [up to 5 parts per million (ppm)] or evaporated, the waste can be classified (and disposed of) as industrial waste; otherwise, dangerous waste rules apply.

\subsubsection{Photographic effluent processing}

The photographic laboratory produces photo waste containing silver residues which, if not treated, must be considered hazardous waste. There is an on board process to reduce the amount of silver found in waste. If the photographic waste is not treated to reduce the silver concentration to less than $5 \mathrm{ppm}$, then the entire silver reduction process must be resumed. If the reduction process is not effective, the photographic waste is classified (and disposed of) as hazardous waste.

If the silver reduction process is successful and reduces the contaminant concentration to less than $5 \mathrm{ppm}$, then the waste can be treated as unregulated industrial waste. The photography manager is responsible for all equipment maintenance procedures, as well as for recording the treatment data and filling in the systematic silver recovery manual.

\subsubsection{Photographic effluent testing}

The environmental officer oversees the weekly testing process and needs to be notified if there are discrepancies or if anything unusual happens during the silver recovery, or if test results contain anomalies. In order to make sure that processed waste has a concentration below $5 \mathrm{ppm}$, the photo manager tests the waste on a 
weekly basis using silver indicating copper foil test strips. The results must be recorded in the Silver Recovery Unit Log.

At least once a month, the photo manager collects two photo waste samples using a sample kit provided by the Photography Service. Samples are then sent to a certified laboratory. A copy of the report must be submitted to the environmental officer and another copy must be kept in the Silver Recovery Unit Log. Processed waste can be tested at any time by the environmental officer or by other authorized personnel.

\subsubsection{Silver content testing procedure}

Before the test (Fig. 3) is started, the glass is cleaned and the persons performing the test must wash their hands to avoid influencing the results. A sample is collected in the beaker at room temperature. The copper foil is inserted into the container, in the solution/sample, and kept there for exactly 20 minutes (EPA-Compliance Silver Indicating Copper Foil Test Strips). Copper is evaluated immediately after it is extracted from the solution:

- If there are no spots resulting from loss of shine, the silver content is below 5 ppm;

- If there are traces of loss of shine (gray or brown), the silver content exceeds 5 ppm.

A copy of the record must be recorded in the Image Silver Recovery Unit Log and another copy must be submitted to the environmental officer. The laboratory results are sent to the environmental officer.

\subsubsection{Disposal of photographic effluents}

Waste with less than 5 ppm silver content is considered non-hazardous industrial waste. It is stored in labeled containers and placed in cold rooms until it is discharged as non-industrial waste. The environmental officer records the number of containers to be unloaded and makes the necessary collection arrangements with a specialized company.

\subsubsection{Ashes resulting from incineration}

Waste streams that can be processed by incineration generate a large amount of ash. Ash must be discharged in accordance with local regulations.

\subsubsection{Ash testing and discharge}

The environmental officer must collect an ash sample of about 1 liter in a sterile container from one of the ash-containing containers. 
The sample, marked as "Ash sample", must be labeled with the ship's name, collection date, the name of the person who collected it. The sample is packaged and forwarded to the on-shore Department of Marine and Technical Operations. The environmental officer must send an e-mail to the Department of Marine and Technical Operations to notify the designated employee that an ash sample is en route for testing. After the test, the results are sent to the environmental officer and a copy to the chief engineer. If there are any unusual findings, the Department of Marine and Technical Operations will contact the ship and investigate. Until the results indicate non-hazardous values, the waste must be treated as hazardous.

\subsubsection{Ash discharge}

The ash must be discharged on shore. It must not be discharged into the water. Any type of ash-containing waste discharged in California must be treated as hazardous waste (California Department of Toxic Substances Control site, Official California Code of Regulations (CCR), Title 22, Division 4.5).

\subsubsection{Medical waste}

The medical unit generates several types of waste that must be processed separately. Dangerous bio-waste can also be generated by guests (e.g. insulin syringes). It is critical to classify such waste correctly, so that the appropriate disposal method can be used. All dangerous bio-waste is to be collected in dedicated red bags and moved straight to the waste collection and processing area before being transferred on land to a company specialized in dangerous bio-waste disposal (Disney Cruise Line, 2016). An alternative consists of on board incineration. Low-level contamination risk singleuse articles that can be washed (e.g. napkins) are collected in yellow bags and transferred to the laundry unit. These yellow and red bags cannot be used in any other circumstances.

Pharmaceutical Products (unused or expired). Most pharmaceutical products with sealed packaging can be returned to the supplier. If possible, this disposal method is preferred over all others. When the packaging is no longer intact, the products are processed on board or transferred on land for further processing. Expired pharmaceutical product disposal must comply with a series of specific requirements. Disposal methods differ from one category of pharmaceutical products to another. The Senior Doctor must oversee the entire process and inform the Staff Captain and Environmental Officer when such waste is ready for discharge. In an effort to minimize waste amounts, the head nurse continuously monitors the expiration dates of all pharmaceutical products.

If found, drugs must be incinerated on board. The Staff Captain, Environmental Officer, Senior Doctor and nurse must oversee the incineration 
process for all narcotics. The doctor must then file a report and submit a copy to the onshore Medical Operations Unit (Disney Cruise Line, 2016).

The medical unit is responsible for keeping a record of all pharmaceutical products that are sent back to the supplier, processed on board or discharged on land. P-coded drugs in 40 CFR 261.33 (e), as well as empty containers used for storing the products, must be treated as dangerous waste (U.S. Government Publishing Office site, 40 CFR 261.33). Drugs not classified as P (also empty containers) are either discharged on land or incinerated.

Sharp waste that can puncture human skin. Such waste must not be collected in the same containers as other dangerous bio-waste. Instead, the dedicated container in the ship's health centre must be used. When the container is almost full (three quarters), it must be sent to a dangerous bio-waste-processing unit. These containers cannot be used for any other waste categories, e.g. red bags or P-coded drugs. However, sharp objects and red bags can be discharged on land and shipped together for further processing.

Sharp industrial waste. Sharp materials are normally used in several on board work areas; they include blades, needles, knives and all objects that can puncture human skin. This type of waste is included in the sharp medical waste category.

Sharp industrial waste must be discharged using the dedicate containers that can be found in several work areas. When necessary, the environmental officer is responsible for replacing them. Full containers are discharged together with other types of sharp materials.

\subsubsection{Pesticide waste}

Pesticides must be returned to the supplier or the contracting company that delivered them on board for processing. As the ship undergoes periodic pest control actions, a minimum amount of pesticides must be stored on board. If necessary to discharge these pesticides, they must be stored in special containers, properly labeled with all MSDS information, and full compliance with the regulations in force must be ensured. In case of an accident, no matter the scale, the environmental officer must be informed.

\subsubsection{Battery management}

Several categories of batteries are used on board, which require different disposal methods (U.S. Clean Harbours, 2011). Alkaline batteries are used in flashlights, radios and remote controls. They are not considered hazardous waste and can be discharged as universal waste.

$\mathrm{Ni}-\mathrm{Cd}$, lithium, silver oxide batteries are used for cameras, mobile phones, laptops, computers and many other portable devices. These batteries are classified as 
hazardous waste and must be discharged in accordance with all hazardous waste disposal regulations.

Lead-acid batteries, similar to car batteries, are found in large equipment units (forklifts, boats). They must be processed as hazardous waste, unless they are recycled by a certified recycling facility.

\subsubsection{Light bulb management}

Mercury-containing light bulbs contain a small amount of mercury that can be harmful to human health and cannot be processed on board. They must be stored and processed as hazardous waste in compliance with the regulations in force. When the necessary amount is collected, the light bulbs are properly documented with a pro forma invoice and sent to a recycling unit where mercury can be extracted.

Fluorescent bulbs are compacted and mercury vapors are retained in the HEPA filter. All waste collected from treated light bulbs must be managed and discharged as hazardous waste (Disney Cruise Line, 2016).

\subsubsection{Management of pressurized aerosol-based cans}

Aerosols in pressurized cans may explode if discharged inappropriately. As such, they are classified as hazardous waste. They can be processed on board in order to remove the hazardous components, after which they can be discharged as unregulated waste.

All aerosol containers must be collected in the waste treatment area and must be kept separate from other types of waste. A container designated for aerosol cans must be available in the waste treatment and processing area. Units that use large amounts of aerosols (e.g. carpenters, theatre and costume technicians) must have separate bins in their work areas for aerosol cans, located at a distance from household waste. Once transferred to the waste management and treatment area, aerosol cans are collected until the container is full, after which the cans are punctured with a special device. As a result, the punctured cans are no longer hazardous and can be collected with the rest of the non-hazardous metal waste and discharged on land.

\subsubsection{Butane canisters}

The steward head and the first steward are responsible for storing, using and tracking butane canisters throughout their use cycle. All movements of butane canisters must be recorded in the butane canister log, also after they reach the waste disposal room. Butane canisters are kept separate from food, in a cabinet on deck 2.

Prior to starting the shift, a food department employee takes over the canisters and records their number, then signs the logbook. At the end of the shift, 
the employee takes all butane canisters and returns them to deck 2, in the flammable object room, after which he or she records them in the butane canister log.

All butane canisters must be used until they are completely empty. The steward head and the first steward check all empty butane canisters to make sure they are completely empty. Once a day, all empty canisters on deck 2 are moved to the waste management area.

The number of empty butane canisters that exit the storage area is recorded in the butane canister log, after which the person in charge signs it to confirm that they were transferred to the waste processing area. The employees in charge of collecting and hauling waste check if the empty butane canisters are properly discharged. Empty butane canisters can be considered as either hazardous waste or nonhazardous waste, if they are punctured with a special device (Disney Cruise Line, 2016).

\subsubsection{Unloading Canisters, Barrels, Containers}

The unloading procedure for waste, recyclables, excess materials, canisters, barrels (empty or full) must comply with the legislation in force and DCL's environmental policy. Moreover, special attention is paid to the nature of the container contents, in order to meet all requirements for any material with particular characteristics.

Barrels or similar containers are normally considered "empty" when all contents have been removed by common practice (pouring/ pumping/suction) and no more than $2.5 \mathrm{~cm}$ ( $1 \mathrm{inch})$ of residue is found on the bottom. Empty steel barrels (55 gallons) and plastic containers of similar size must have the top and/or bottom parts cut off before being unloaded as regulated waste.

Containers containing hazardous materials or oily waste must be unloaded in accordance with the regulations applicable to the substances in question. Empty containers can be unloaded as unregulated waste, except for containers used for storing acutely hazardous waste listed in 40 CFR 261.31/.32/.33e (Cornell Law School Site, 40 CFR Part 261, Subpart D). These containers require three rinses once the contents have been emptied.

DCL promotes the recycling of empty containers and the return of excess material to suppliers. Thus, waste and container collection must be duly planned so that all waste is unloaded and transferred to specialized waste processing companies before 13:00 on the landing day. The environmental officer is responsible for informing the Procurement and Logistics Department in order to set the time and the number of containers to be replaced. On the landing day, the environmental officer must inspect all containers to make sure they are empty and labeled correctly, according to the contents and the information found in the pro forma invoice. When 
all requirements are met, the environmental officer authorizes the unloading of the containers (Disney Cruise Line, 2016).

The environmental officer monitors the unloading of waste, recyclable or excess materials that have an environmental impact (including empty containers) and ensures compliance with the requirements and regulations in force.

\subsection{Oily waste}

Non-food used oil, Vaseline, kitchen oil and/or oil-contaminated waste are recycled or transferred into the liquid or solid residue tank located in the engine room, and subsequently unloaded at the Canaveral harbor every 3 weeks (40 tons).

DCL's internal policy does not allow the burning of oily waste on board its ships. If necessary, the liquid or solid residue tank is emptied, and its contents are transferred to a land-based facility. The chief engineer is responsible for contacting the director of technical operations in due time to make the necessary arrangements for the waste transfer. The director of technical operations must confirm the date and time for the procedure.

Used cooking oil and grease must be separated from all other waste, and processed and unloaded in accordance with the legislation in force and DCL's regulations. This type of waste must not be processed using food waste grinders or discharged into kitchen sewers (Disney Cruise Line, 2016).

All oil waste must be cooled, and then collected in properly labeled containers ("Used cooking oil/Grease waste"). Oily waste containers must be transferred to the waste treatment area on deck 1 for filtering or recycling. Waste that cannot be filtered or recycled must be handed over to the person in charge of the waste management facility, who in turn sends the waste to the incinerator.

\subsection{Paint waste}

Paint waste includes any component or blend of paint, catalysts, solvents, diluents, as well as cloths, brushes, paint-stained clothes, or other similar objects. Unless authorized by the environmental officer, no one is allowed to mix paint waste with any other type of waste. Paint waste must never be poured into drains or sewers.

All dry paint waste or dry paint waste containers must be transferred to the waste management area. Once there, the environmental officer and the person in charge of the waste management area decide which disposal method to use. Dry paint waste can be unloaded as regular waste. Paint containers must be emptied, cleaned and left to dry (Disney Cruise Line, 2016).

Liquid paint must be processed and unloaded in accordance with regulations applicable to hazardous waste. Liquid paint must be transferred from its containers to a special paint collection container labeled "hazardous paint waste" and stored in 
a suitable, designated place. When the container is full, the environmental officer must be notified in order to start preparing all the necessary unloading procedures for hazardous waste.

Any diluent must be unloaded as hazardous waste and can be discharged into the waste paint collection container. Catalysts cannot be poured into the paint waste containers because of the possible side effects. Catalysts must be collected separately and handled as hazardous waste.

Paint-containing aerosol cans must be punctured and emptied using a special device. They must then be labeled and unloaded as unregulated waste. Aerosol cans that cannot be punctured are considered hazardous waste. Solvent-stained cloths must be stored in vapor-tight, properly labeled containers, and stored in the paint cabinet (or other designated location) until unloaded as hazardous waste (Disney Cruise Line, 2016).

\subsection{Refrigerants}

CFCs (chlorofluorocarbons) and HCFCs (hydrochlorofluorocarbons) - The US Clean Air Act of 1990 (USA) set stringent regulations prohibiting the ventilation of ozonedepleting compounds while using various types of appliances, as well as the disposal of such appliances, e.g. air conditioners and refrigeration equipment. Refrigerants that cannot be used or defective refrigerants must be collected and unloaded on land or returned to the supplier for proper disposal (U.S. Environmental Protection Agency, 1990).

\section{On board logs and reports}

According to MARPOL and for any other applicable requirements, there is an on board record keeping system that documents the processing and/or unloading of any waste.

The system includes:

1. The waste log

2. The hazardous waste log

3. The oil management log

4. The used water $\log$ (gray and black water)

5. NPDES Records (National Pollutant Discharge Elimination System)

6. Copies of minutes/report and receipts for returning hazardous waste

7. Receipts from suppliers of plastic and other materials (any receipt received by the procurement and logistics unit is also transmitted to the ship crew)

The environmental officer is responsible for the waste management documentation, with the exception of the oil management and used water logs, which are managed by the chief engineer. These documents are kept in a controlled 
on board location. They are examined at regular intervals and signed by the captain and/or by the chief engineer. All these logs and registration documents are available for inspection by any authorized regulatory body or auditor.

\subsection{Waste log}

The waste log is kept on the Navigation Bridge. The environmental officer writes in all entries. No other person can make an entry except for those specially trained by the captain. The entries must be clearly legible and written in ink. The waste log is available for inspection by any authorized person or organization. Once the entries are completed, the captain examines and validates each page.

Environmentally safe residual chemical products, used in combination with deck cleaning water, are considered operational waste and the total amounts of water used during the process must be recorded in the waste $\log$ in category F; the estimated amount must be expressed in cubic meters.

\subsection{Hazardous waste log}

The environmental officer is responsible for keeping the hazardous waste log. This document contains records of all materials unloaded as hazardous waste or stored aboard the ship and expected to be unloaded.

\subsection{Oil management log}

At the end of each relevant operation, the second engineer completes and signs the oil management log. The necessary data for oily products can be found in the first chapter of each oil log. The second engineer fills in and signs the section of the oil log for which he or she is responsible. The designated engineer for operations records information on fuel, diesel or lubricating oil. The second engineer records, on a weekly basis, entries on sludge content, transfer of bilge water to the bilge tank, etc. in section $C$ of the oil log. The chief engineer signs each page of the $\log$, and the environmental officer inspects it before the Captain signs each completed page (Disney Cruise Line, 2016).

\subsection{Used water log}

The used water log is kept in the engine control room. Engineers record the type of water, the amount in $\mathrm{m}^{3}$, the time and the discharge position of the Advanced Wastewater Purification System (AWPS). The maintenance and monitoring criteria in NPDES, section 5 (U.S. Environmental Protection Agency (EPA), National Pollutant Discharge Elimination System (NPDES), 2013) must be met.

\subsection{NPDES records}


If requested, the documentation to be provided to the Environmental Protection Agency or its authorized representative includes:

- Annual inspection of ships

- Latest Dry Dock inspection reports

- Routine visual inspections

- Annual report

- Routine analytical inspection

- EPA receipt confirmations

- Recordings of trainings kept according to NPDES authorization requirements

These documents must be kept on board for three years.

\section{White Data Box}

White Box processes bilge water evacuation and the oil content in the evacuated water.

Bilge water is directed into a specific tank, from which it passes through the purification and filter system which separates oil from water. The oil is sent to the sludge tank, while the water reaches the white box, where the oil content is checked. The White Box has 3 valves that control the oil concentration in the evacuated water. The oil content in the evacuated water must be $\leq 15 \mathrm{ppm}$ (United Nations, International Maritime Organization, 2011). If, after passing the first valve, the oil content is $>15 \mathrm{ppm}$, the second valve closes automatically, and the water passes again through the purification system.

Engineers store the white data box and the original data on the ship's servers. The white box and water evacuation are only controlled by engine engineers. The environmental officer keeps a back-up, an archive of White Box data, and all charts in a special folder on drive C: of a computer located in the Environmental Office. The White Box data contains the location, time, flow, and ppm oil in evacuated bilge water.

The amount of oily waste unloaded in Port Canaveral, for large ships such as Disney Fantasy, is 40 tons every three weeks, and 30-40 tons/week for bilge water. Every month, the environmental officer accesses the server data using the White Box software and completes the following steps:

- Transfers data and creates diagrams.

- Saves a copy of monthly data and the graph found on the Environmental Office computer.

- Makes sure the data is accessible to the inspectors, agents and officers of the other ship who wish to review the information.

- Submits a copy of monthly data to the technical operations department for AMOS software registration. 
Whiteboard data is kept for three years, similarly to the Oil log (United Nations, International Maritime Organization, 2011).

\section{Equipment used for waste processing and recycling, and equipment maintenance}

\subsection{The incinerator room equipment consists of the following:}

- Dry waste shredder

- Hydrants

- Discharge/unloading slides (Disney Magic and Disney Wonder)

- Ash containers

- Ash packing equipment

- Waste sorting table

- Dry waste silos

- Wet waste silos

- Incinerators

The incineration room is the central waste disposal and management area.

\subsection{Waste processing and recycling equipment}

- Glass crusher

- Aluminum/tin compactor (Fig. 4)

- Paper shredder (Fig. 5)

- Heavy duty crusher (only Disney Magic and Disney Wonder)

- Cardboard compactor/baler

- Storage space for recyclable materials

- Fluorescent lamp crusher

- Aerosol puncturing device and storage unit

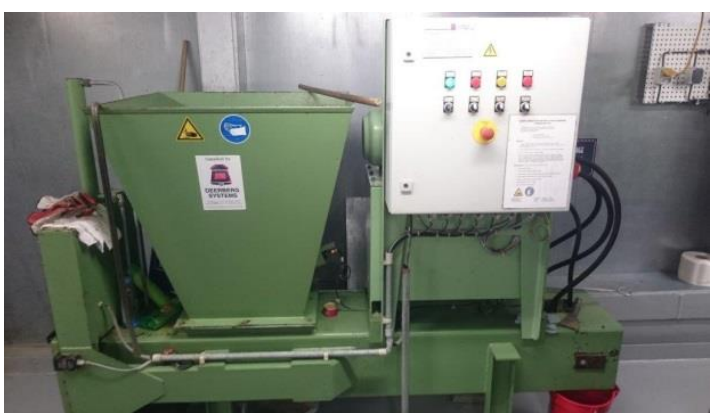

Figure 5: Paper shredder

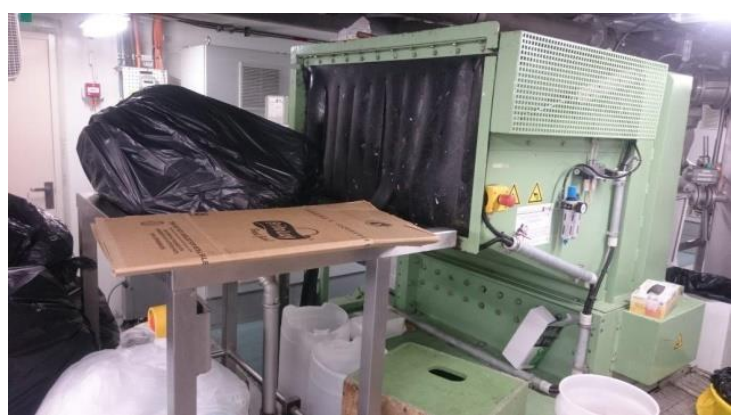

Figure 4: Aluminum compactor 
The cold storage room is used for the temporary storage of non-flammable hazardous waste before being processed or discharged on land, as well as for any waste likely to be affected by heat.

It is important to note that the waste treatment equipment must operate in accordance with the manufacturer's instructions, including the safety measures.

There are three main waste processing flows in the waste management area:

- Dry waste treatment (flammable)

- Wet waste treatment (foods)

- Recyclable/non-flammable waste treatment

\subsubsection{Wet waste treatment process - Waste pulper system}

Wet waste consists of materials that can be processed by the pulper system.

Food waste is directed to the pulper system. All pulpers are connected to a pipeline system that pumps wet waste into the incinerator room. On Disney Magic and Disney Wonder, food waste is processed in water extractors that transfer it to wet waste silos after separating the water. On Disney Dream and Disney Fantasy, the transfer uses a vacuum system instead of water.

The wet waste handling equipment inside the incineration room requires daily maintenance and cleaning in order to reduce odors and avoid malfunctions. Rinsing the equipment and keeping it clean are essential for ensuring proper operation. Waste management operators perform daily maintenance procedures. If the equipment does not work properly or if any problems occur, the engineering department is notified.

The wet waste system is made up of several pulpers located along the ship. The pipeline system to which these pulpers are connected can be separated into two individual operating subsystems, which makes it more reliable in case one of the subsystems fails.

In the event of a complete malfunction of the wet waste system, all waste must be collected in containers (based on color codes) that can be sealed with a lid. The containers are transferred to the cold storage room temporarily. In the unlikely event that the failure lasts so long that the storage capacity is fully utilized, overboard discharge of wet waste must be considered.

\subsubsection{Recycling processes}

\section{Densifier/compactor}

Tin and aluminum cans are collected in separate containers in the sorting and processing area, after which they are placed in the densifier. Tin and aluminum are compacted separately, as the recycling company offers a higher price if tin and 
aluminum are not mixed together. The densifier is used in accordance with the manufacturer's instructions, including safety measures.

\section{Baler}

Clean cardboard and other dry materials that are recycled can be stored in large bales, using the baler located in the sorting and processing area. The baler must be used in accordance with the manufacturer's instructions, which also includes safety measures.

\section{Glass crushers}

Damaged glass and porcelain are collected and transported via service lifts into the waste management area, where they must be sorted. Glass will be crushed immediately, stored, and subsequently unloaded from the ship. The glass crusher is used in accordance with the manufacturer's instructions, including safety measures. If the crushed glass is recycled, porcelain cannot be added to the mix.

\section{Malfunctions of recycling equipment}

If there are malfunctions of recycling equipment such as crushers, balers or tin/aluminum can densifiers, more space is needed to temporarily store the waste until it is unloaded. Recycled products can be transferred on board without any prior processing. However, all recyclable materials must be sorted.

The Engineering Department is responsible for the maintenance and repair of waste recycling equipment, including that found in the waste management area.

\section{Conclusions}

This paper presents detailed information about on board waste collection, sorting, transport, processing, storage and discharge procedures, waste logs and reports, White Data Box, the equipment used for waste processing and recycling, and equipment maintenance.

The study concludes that the DCL company is committed to minimizing its fleet's environmental impact by means of adopting new technologies, generating less waste, training its staff and instructing its guests, and raising awareness on environmental issues.

All crew members must fully comply with the DCL company's environmental requirements and policy. Both employees and customers must pay attention to the practices that can result in accidental pollution.

For sanitary and safety reasons, any collected waste must be transferred to the waste treatment area as directly as possible. Waste collection procedures and the prevention of improper waste disposal are carefully monitored at all times. DCL makes continuous efforts to minimize waste amounts and associated risks on its ships. This entails employing the appropriate storage, use and disposal procedures, 
and extends all the way to operation and event planning, and supply and consumable sourcing.

On board waste management is a requirement that is applied equally to each crew member and unit. All heads of unit must check: that waste collection points are set up with appropriate containers for each operation, that efficient procedures for sorting and transporting waste to the waste treatment area are put in place, and that all crew members are trained on the correct waste management methods.

Waste processing and unloading procedures are judiciously applied to the following categories of waste: food waste; hazardous waste; special waste; oily waste; paint waste; refrigerants. The heads of unit are responsible for their areas and any other areas that may be assigned to them, and must make sure that all waste management procedures are respected.

According to MARPOL and for any other applicable requirements, on board DCL ships there is a well-established system for keeping waste management records, which documents the processing, discharging or unloading of any waste. The equipment used for waste processing and recycling is properly serviced and used, in accordance with the manufacturers' instructions, including safety measures. In 2013, the Cruise Industry Environmental Report Card ranked the cruise line first in terms of environmental responsibility (Elks, 2013). The company pays utmost attention to all national and international environmental conventions, laws and regulations in force. DCL's environmentally friendly vision is best described by these values and actions: thorough bookkeeping, monitoring, double-checking, awareness, continuous communication.

\section{Acknowledgment}

The two authors contributed equally in conducting the research and preparing the manuscript.

\section{References}

BRIDA J.G., ZAPATA S., 2010. Cruise tourism: Economic, socio-cultural and environmental impacts, International Journal of Leisure and Tourism Marketing, 1:3, p. 205-226

BURGIN S., HARDIMAN N., 2011. The direct physical, chemical and biotic impacts on Australian coastal waters due to recreational boating, Biodiversity and Conservation, 20:4, p.683-701, DOI: $10.1007 / \mathrm{s} 10531-011-0003-6$

ButT N., 2007. The impact of cruise ship generated waste on home ports and ports of call: A study of Southampton, Marine Policy, 31:5, p. 591-598

CAlifornia DePartment of TOXIC Substances CONTROL site, Official California Code of Regulations (CCR), Title 22, Division 4.5, https://www.dtsc.ca.gov/LawsRegsPolicies/Title22/

Cornell LAW SCHOOL Site, 40 CFR Part 261. Subpart D - Lists of Hazardous Wastes, § 261.31, § 261.32, § 261.33e, https://www.law.cornell.edu/cfr/text/40/part-261/subpart-D

Disney CRUISE Line, 2016. Safety Management System, Environmental Aspects, England: Magical Cruise Company Limited

ElKS J., 2013. Disney Scores the Only " $A$ " on Cruise Industry Environmental Report Card, http://www.sustainablebrands.com/news_and_views/communications/jennifer-

elks/disney-scores-only-cruise-industry-environmental-report- 
EPA-Compliance Silver Indicating Copper Foil Test Strips, www.silverprofit.com/PDF\%20Files/stf50_instr.pdf

JOHNSON D. (2002). Environmentally sustainable cruise tourism: a reality check. Marine Policy, 26:4, p. 261-270. https://doi.org/10.1016/S0308-597X(02)00008-8

Kizielewicz J., LuKovic T., 2015. Negative Impact of Cruise Tourism Development on Local Community and the Environment, Information, Communication and Environment: Marine Navigation and Safety of Sea Transportation, p.243-250

LASSERRE F., TETU P.L., 2015. The cruise tourism industry in the Canadian Arctic: analysis of activities and perceptions of cruise ship operators, Polar Record, 51:1, p.24-38, DOI: $10.1017 / S 0032247413000508$

LETSON D., SumAN D., SHIVLANI M. (1998). Pollution prevention in the coastal zone: An exploratory essay with case studies, Coastal Management, 26:3, p.157-175. https://doi.org/10.1080/08920759809362350

Manoiu V.-M., AntOnescu M. (2017). Disney Cruise Line Environmental Management. Part I: Environmental Policy and Waste Management on Cruise Itineraries, Papers of the "Dimitrie Cantemir" Geographic Seminar, 45:2

ManoIU V.-M. (2018). Waste Collection, Sorting and Storage and Food Waste Management on Disney Cruise Line Ships, Proceedings Volume of the $12^{\text {th }}$ International Scientific Forum - ISF 2018, Prague, European Scientific Institute. DOI:10.19044/esj.2018.c4p1

Manoiu V.-M. (2018). Dangerous and Medical Waste Management on Board Disney Cruise Line Company Ships. Accepted article, ADVED 2018 - 4th International Conference on Advances in Education and Social Sciences, Istanbul, October 15-17, 2018.

MoreHOUSE C., KOCH D., 2003. Alaska's cruise ship initiative and the commercial passenger vessel environmental compliance program, OCEANS 2003 MTS/IEEE: Conference on Celebrating the Past - Teaming Toward the Future, p.372-375

Polglaze J., 2003. Can we always ignore ship-generated food waste?, Marine Pollution Bulletin, 46:1, p. 33-38, DOI: 10.1016/S0025-326X(02)00324-7

SRINIVASAN M., SWAIN G.W., 2007. Managing the use of copper-based antifouling paints, Environmental Management, 39:3, p.423-441, DOI: 10.1007/s00267-005-0030-8

Strazza C., Del Borghi A., Gallo M., Manariti R., Missanelli E., 2015. Investigation of green practices for paper use reduction on board a cruise ship - a life cycle approach, The International Journal of Life Cycle Assessment, 20:7, p. 982-993, https://doi.org/10.1007/s11367-0150900-0

Svaetichin I., Inkinen T., 2017. Port Waste Management in the Baltic Sea Area: A Four Port Study on the Legal Requirements, Processes and Collaboration, Sustainability, 9:5, article no.699, DOI:10.3390/su9050699

UlNiKOVIC V.P., VUKIC M., NiKOLIC R., 2012. Assessment of vessel-generated waste quantities on the inland waterways of the Republic of Serbia, Journal of Environmental Management, Vol.97, p.97-101, DOI: 10.1016/j.jenvman.2011.11.003

UnITED NATIONS - INTERNATIONAL MARITIME ORGANIZATION, 2011. International Convention for the Prevention of Pollution from Ships (MARPOL), 5th edition, IMO Publishing.

U.S. Clean Harbours, 2011. Battery Packing Protocol V15, Washington, DC: U.S. Government Printing Office.

U.S. Environmental Protection Agency, 1990. Clean Air Act, Washington, DC: U.S. Government Printing Office.

U.S. EnVironmental Protection Agency (EPA) - National Pollutant Discharge Elimination System (NPDES), 2013. Vessel General Permit for Discharges Incidental to the Normal Operation of Vessels (VGP), Washington, DC: U.S. Government Printing Office, https://www3.epa.gov/npdes/pubs/vgp_permit2013.pdf

U.S. GOVERNMENT PUBLISHING OFFICE site. 40 CFR 261.33 - Discarded Commercial Chemical Products, Off-Specification Species, Container Residues, and Spill Residues Thereof. https://www.gpo.gov/fdsys/granule/CFR-2012-title40-vol27/CFR-2012-title40-vol27sec261-33

Wilewska-Bien M., Granhag L., ANDERSSON K., 2016. The nutrient load from food waste generated onboard ships in the Baltic Sea, Marine Pollution Bulletin, 105:1, p. 359-366, https://doi.org/10.1016/j.marpolbul.2016.03.002 
